\title{
Resíduo de sisal incorporado à substrato comercial na formação de mudas de jiló e brócolis
}

\section{Sisal residue incorporated into the commercial substrate in the formation of eggplant and broccoli seedlings}

\author{
Marlon Jocimar Rodrigues da Silva ${ }^{1 *}$, Nardélio Teixeira dos Santos ${ }^{2}$, Élica Santos Rios ${ }^{3}$, Aldérica da Cunha Oliveira ${ }^{3}$, Diego \\ Alves de Souza ${ }^{4}$
}

Resumo: O objetivo do trabalho foi avaliar o efeito da incorporação de resíduo de sisal ao substrato comercial sobre a emergência e a qualidade de mudas de jiló e brócolis. Os experimentos foram realizados em casa de vegetação com sombrite 50\% no Departamento de Tecnologia e Ciências Sociais da UNEB, em Juazeiro, BA, utilizando-se sementes comerciais de jiló e brócolis. Nas duas espécies, os tratamentos consistiram na incorporação de diferentes porcentagens de resíduo de sisal (RSL) ao substrato comercial Tropstrato ${ }^{\circledR}$. Foi incorporado: 0, 10, 20, 30, 40, 50, 60 e $80 \%$ do RSL ao substrato comercial. Determinou-se o índice de velocidade e a porcentagem de emergência das plântulas, e aos 26 dias após a semeadura foram determinadas as seguintes características: comprimento de raiz e da parte aérea, diâmetro do colo, número de folhas, volume de raízes e massa seca da parte aérea e de raízes. O resíduo de sisal pode ser incorporado ao substrato comercial Tropstrato ${ }^{\circledR}$ na formação de mudas de jiló e brócolis sem interferir na sua qualidade, sendo mais indicada a incorporação $50 \%$ do resíduo de sisal ao substrato comercial.

Palavras-chaves: Agave sisalana, Solanum gilo, Brassica olerarea, plântulas

\begin{abstract}
The aim of this study was to evaluate the effect of sisal residue incorporation the commercial substrate on the emergency and the quality of eggplant and broccoli seedlings. The experiments were performed in a greenhouse with $50 \%$ shade at Department of Technology and Social Sciences of UNEB, in Juazeiro, BA, using commercial seeds of eggplant and broccoli. In both species, the treatments consisted of the incorporation of different sisal residue percentages (SLR) the commercial substrate Tropstrato ${ }^{\circledR}$. Was incorporated: 0, 10, 20, 30, 40, 50, 60 and 80\% of SLR at the commercial substrate. Determined the speed index and the percentage of seedling emergence and at 26 days after sowing were determined the following characteristics: length of root and shoot, stem diameter, number of leaves, root volume and dry weight of shoots and roots. The sisal residue can be incorporated into the commercial substrate Tropstrato ${ }^{\circledR}$ at the formation of eggplant and broccoli seedlings without impinging on the quality, 50\% incorporation of more appropriate sisal residue the commercial substrate.
\end{abstract}

Key words: Agave sisalana, Solanum gilo, Brassica olerarea, seedlings

\footnotetext{
*Autor para correspondência

Recebido para publicação em 08/05/2015; aprovado em 28/09/2015

${ }^{1}$ Eng. Agr. M. Sc., Faculdade de Ciências Agronômicas, Universidade Estadual Paulista "Júlio de Mesquita Filho" (FCA/UNESP), 18.610-307, Botucatu-SP, E-mail: marlonjocimar@gmail.com

${ }^{2}$ Eng. Agr. M. Sc., Centro de Ciências e Tecnologias Agropecuárias, Universidade Estadual do Norte Fluminense (LMGV/UENF), 28.013-602, Campos dos Goytacazes-RJ, E-mail: nardeliosantos@gmail.com

${ }^{3}$ Eng. Agr. M. Sc., Departamento de Fitotecnia e Ciências Ambientais, Universidade Federal da Paraíba (UFPB/CCA/PPGA), 58.397-000, Areia-PB, E-mail: lk.rios@hotmail.com; aldericac.oliveira@hotmail.com

${ }^{4}$ Eng. Agr., Departamento de Tecnologia e Ciências Sociais, Universidade do Estado da Bahia (DTCS/UNEB), 48.905-680, Juazeiro-BA, E-mail: souzadigoalves@yahoo.com.br
} 


\section{INTRODUÇÃO}

Para o bom desenvolvimento de plântulas de jiló (Solanum gilo Raddi), brócolis (Brassica oleracea var. Italica) e, de modo geral, outras hortaliças, é de fundamental importância a utilização de sementes e mudas de boa qualidade, tornando-se necessário o estudo de métodos de produção de mudas que resultem em plantas com qualidade agronômica necessária para plantios comerciais (LAVIOLA et al., 2006). De acordo com Vale et al. (2004), o substrato tem papel fundamental nesse processo, pois exerce influência marcante na arquitetura do sistema radicular e no estado nutricional das plantas.

O substrato deve apresentar características físicas, químicas e biológicas apropriadas, possibilitando a germinação, emergência e o bom desenvolvimento inicial das plântulas (MAURI et al., 2010). Entre os materiais frequentemente utilizados para a formação de mudas de hortaliças, estão o substrato comercial Tropstrato ${ }^{\circledR}$ $\left(\right.$ Plantmax $\left.^{\circledR}\right)$ e a vermiculita, porém outros materiais têm sido estudados para serem utilizados em misturas, tais como a casca de arroz carbonizada (GOMES et al., 2008), a fibra da casca de coco verde (CARRIJO et al., 2002) e o resíduo de algodão (COSTA et al., 2007). Esses e outros compostos podem ser utilizados objetivando promover melhores condições físicas e químicas para o crescimento das plântulas (GRASSI FILHO et al., 2004) e reduzir o custo de produção das mudas.

Na seleção de materiais para uso como componentes de substratos, o resíduo do sisal (Agave sisalana Perrine), oriundo do desfibramento da folha da planta, surge como uma alternativa promissora, podendo ser economicamente viável e racionalmente aproveitado, uma vez que o mesmo normalmente é descartado pelas indústrias. A avaliação de resíduos para aproveitamento como substrato agrícola é uma alternativa importante para a reciclagem desses materiais, contribuindo para a adoção de formas de utilização e resultando na minimização dos impactos causados pelos mesmos ao meio ambiente (COSTA et al., 2013).

Informações a respeito do uso do resíduo de sisal como substrato na formação de mudas de hortaliças são escassas na literatura. Assim, o objetivo do trabalho foi avaliar o efeito da incorporação de resíduo de sisal ao substrato comercial sobre a emergência e a qualidade de mudas de jiló e brócolis.

\section{MATERIAL E MÉTODOS}

Os experimentos foram realizados no Departamento de Tecnologia e Ciências Sociais da Universidade do Estado da Bahia, em Juazeiro, BA, situado a 9²5'43” S, 40³2'14”' W, e $384 \mathrm{~m}$ de altitude, durante os meses de março a maio 2011 , em casa de vegetação com sombrite de 50\%. O clima da região é classificado, segundo Köepen, como tipo Bswh, correspondente a um clima muito quente, semiárido e com estação chuvosa limitada. A precipitação média anual da região é de $529 \mathrm{~mm}$ (TEIXEIRA et al., 2010). Durante a condução dos experimentos, os dados meteorológicos foram obtidos pela Estação de Meteorologia do DTCS/UNEB. Os valores médios de temperatura e umidade relativas do ar foram de $26{ }^{\circ} \mathrm{C}$ e $68,1 \%$, respectivamente.

Foram realizados dois experimentos simultaneamente, com duas espécies hortícolas, jiló e brócolis. Em ambos, foi utilizado o delineamento experimental inteiramente casualizado, com oito tratamentos e quatro repetições, com 40 sementes por repetição. Como área útil, foram consideradas 18 células centrais por parcela, sendo as laterais consideradas bordaduras.

Nas duas espécies, os tratamentos consistiram na incorporação de diferentes porcentagens de resíduo de sisal (RSL) ao substrato comercial Tropstrato ${ }^{\circledR}$. Foi incorporado: 0, 10, 20, 30, 40, 50, 60 e $80 \%$ de RSL ao substrato comercial. O resíduo de sisal foi obtido a partir do desfibramento da folha do sisal.

A semeadura do jiló e do brócolis foi feita de forma manual, sendo realizada em bandejas de isopor, com 176 células, preenchidas com os substratos mencionados, colocando-se uma semente por célula. Para a irrigação foi utilizado regador de crivo fino, sendo feita diariamente, pela manhã e à tarde.

Nas duas espécies, foram avaliados o índice de velocidade (IVE) (MAGUIRE, 1962) e a porcentagem de emergência das plântulas, determinado através de contagens diárias das plântulas emergidas até a estabilização da emergência das mesmas, ocorrida aos 13 dias após a semeadura (DAS) para o jiló e aos 15 DAS para o brócolis.

Aos 26 DAS, foram determinadas as seguintes características das duas espécies: comprimento de raiz e de parte aérea $(\mathrm{cm})$, diâmetro do colo $(\mathrm{mm})$, número de folhas, volume de raiz $\left(\mathrm{cm}^{3}\right)$, massa seca de raiz e da parte aérea (mg). Para essas avaliações, foram utilizadas 10 plântulas por parcela, as quais foram sorteadas aleatoriamente.

Os comprimentos de raiz e da parte aérea foram obtidos utilizando régua graduada em $\mathrm{mm}$; o diâmetro do colo foi determinado com auxílio de paquímetro digital; e a determinação do volume de raízes foi realizada colocando-se as raízes em proveta graduada, contendo um volume conhecido de água. Pela diferença, obteve-se a resposta direta do volume de raízes, pela equivalência de unidades $(1 \mathrm{ml}=1$ $\mathrm{cm}^{3}$ ). Para determinação das massas secas de raiz e parte aérea as plântulas foram lavadas, para remoção do substrato aderido às raízes, acondicionadas em sacos de papel e colocadas em estufa com circulação forçada de ar, a $60{ }^{\circ} \mathrm{C}$, até obtenção de massa constante, sendo posteriormente pesadas em balança de precisão $(0,0001)$.

Os dados obtidos foram submetidos à análise de variância, sendo as médias comparadas entre si pelo teste Tukey, a 5\% de probabilidade, através do programa computacional ASSISTAT (SILVA e AZEVEDO, 2002).

\section{RESULTADOS E DISCUSSÃO}

Não houve efeito significativo dos diferentes substratos na porcentagem e no índice de velocidade de emergência (IVE) de plântulas de jiló (Tabela 1), indicando que a incorporação de até $80 \%$ de resíduo de sisal (RSL) ao substrato comercial Tropstrato ${ }^{\circledR}$ não interferiram nessas características. 
Tabela 1 - Características de plântulas de jiló cultivadas em substratos compostos por diferentes proporções do resíduo de sisal (RSL) incorporado ao substrato comercial Tropstrato ${ }^{\circledR}$. Juazeiro-BA, 2011

\begin{tabular}{|c|c|c|c|c|c|c|c|c|c|}
\hline \multirow{2}{*}{ Substrato $^{1}$} & \multicolumn{9}{|c|}{ Características $^{2}$} \\
\hline & IVE & $\% \mathrm{E}(\%)$ & CPA (cm) & $\mathrm{CR}(\mathrm{cm})$ & DC (mm) & NF & $\operatorname{VR}\left(\mathrm{cm}^{3}\right)$ & $\begin{array}{c}\text { MSPA } \\
(\mathbf{m g})\end{array}$ & $\begin{array}{c}\text { MSR } \\
\text { (mg) }\end{array}$ \\
\hline $0 \%$ RSL & $4,51 \mathrm{a}$ & 78,75 a & $1,48 \mathrm{~b}$ & $13,84 \mathrm{a}$ & $0,84 \mathrm{a}$ & $2,40 \mathrm{a}$ & $0,125 \mathrm{a}$ & $2,3 \mathrm{a}$ & $9,0 \mathrm{a}$ \\
\hline $10 \%$ RSL & $5,23 \mathrm{a}$ & 84,38 a & $1,63 \mathrm{ab}$ & $13,79 \mathrm{a}$ & $0,78 \mathrm{ab}$ & $2,38 \mathrm{a}$ & $0,125 \mathrm{a}$ & $1,8 \mathrm{a}$ & $7,0 \mathrm{ab}$ \\
\hline $20 \% \mathrm{RSL}$ & $4,77 \mathrm{a}$ & $80,00 \mathrm{a}$ & $1,63 \mathrm{ab}$ & $14,25 \mathrm{a}$ & $0,63 \mathrm{bc}$ & $2,30 \mathrm{a}$ & $0,125 \mathrm{a}$ & $1,7 \mathrm{a}$ & $6,0 \mathrm{~b}$ \\
\hline $30 \%$ RSL & $5,51 \mathrm{a}$ & $93,12 \mathrm{a}$ & $1,62 \mathrm{ab}$ & $13,64 \mathrm{a}$ & $0,55 \mathrm{c}$ & $2,06 \mathrm{a}$ & $0,137 \mathrm{a}$ & $1,4 \mathrm{a}$ & $6,0 \mathrm{~b}$ \\
\hline $40 \%$ RSL & $5,32 \mathrm{a}$ & 88,75 a & $1,69 a b$ & $13,14 \mathrm{a}$ & $0,72 \mathrm{abc}$ & $2,19 \mathrm{a}$ & $0,100 \mathrm{a}$ & $1,6 \mathrm{a}$ & $7,0 \mathrm{ab}$ \\
\hline $50 \%$ RSL & $5,68 \mathrm{a}$ & $93,12 \mathrm{a}$ & $1,75 \mathrm{a}$ & $14,44 \mathrm{a}$ & $0,74 \mathrm{abc}$ & $2,29 \mathrm{a}$ & $0,137 \mathrm{a}$ & $1,7 \mathrm{a}$ & $8,0 \mathrm{ab}$ \\
\hline $60 \%$ RSL & $5,88 \mathrm{a}$ & $98,12 \mathrm{a}$ & $1,60 \mathrm{ab}$ & $12,50 \mathrm{a}$ & $0,57 \mathrm{c}$ & $2,09 \mathrm{a}$ & $0,125 \mathrm{a}$ & $1,4 \mathrm{a}$ & $6,0 \mathrm{~b}$ \\
\hline $80 \%$ RSL & $5,75 \mathrm{a}$ & $98,12 \mathrm{a}$ & $1,64 a b$ & $12,89 \mathrm{a}$ & $0,57 \mathrm{c}$ & $2,33 \mathrm{a}$ & $0,140 \mathrm{a}$ & $1,9 \mathrm{a}$ & $8,0 \mathrm{ab}$ \\
\hline $\mathrm{CV}(\%)$ & 12,29 & 12,75 & 5,71 & 12,69 & 13,09 & 10,67 & 30,08 & 23,96 & 22,32 \\
\hline
\end{tabular}

${ }^{\mathrm{l}}$ Médias seguidas de mesma letra nas colunas não diferem entre si pelo teste Tukey, a 5\% de probabilidade.

${ }^{2}$ IVE: Índice de velocidade de emergência; \%E: porcentagem de emergência; CPA: comprimento de parte aérea; CR: comprimento de raiz; DC: Diâmetro de colo; NF: Número de folhas; VR: volume de raiz; MSPA: massa seca da parte aérea; MSR: massa seca de raiz.

As diferentes porcentagens do RSL incorporadas ao substrato comercial não diferiram significativamente entre si quanto ao comprimento de raiz das plântulas de jiló, no entanto quando avaliado o comprimento da parte aérea, verificou-se que os maiores valores foram obtidos quando incorporou-se $50 \%$ do RSL ao substrato comercial, ao passo que o menor comprimento de parte aérea das plântulas foi verificado quando se utilizou apenas o Tropstrato ${ }^{\circledR}$, sendo os valores de 1,75 e 1,48 cm, respectivamente. A iniciação do crescimento radicular e, consequentemente, da parte aérea está relacionado à boa capacidade de aeração, drenagem, retenção e disponibilidade de água dos substratos (OLIVEIRA et al., 2008). Esses fatores certamente foram favorecidos pela incorporação do RSL, principalmente quando incorporado em $50 \%$, favorecendo o crescimento inicial da parte aérea das plântulas.

O maior diâmetro de colo das plântulas foi verificado quando utilizado apenas o substrato comercial, embora não tenha diferido significativamente dos substratos com incorporação de 10, 40 e 50\% do RSL. Santos et al.(2010) verificaram que a utilização de vermicomposto ou da mistura de vermicomposto com vermiculita (3:1) como substrato promoveram diâmetro de colo semelhantes àqueles obtidos quando se utilizou apenas o Plantmax ${ }^{\circledR}$ na produção de mudas de pimentão. Esses autores relatam que o maior diâmetro de colo pode ser demonstrativo de plantas mais vigorosas.
O número de folhas por plântula, o volume de raízes e a massa seca da parte aérea das plântulas de jiló não apresentaram diferenças significativas em função dos diferentes substratos estudados. Silveira et al. (2002) obtiveram maior número de folhas e maior valor de massa seca da parte aérea em plântulas de tomateiro utilizando substratos compostos por Plantmax ${ }^{\circledR}(\mathrm{P})+$ pó de coco $(\mathrm{PC})+$ húmus de minhoca $(\mathrm{H})(1: 1: 1), \mathrm{P}+\mathrm{PC}(1: 1)$, e $\mathrm{P}+\mathrm{H}(1: 1)$, comparados à utilização do Plantmax ${ }^{\circledR}$ individualmente, evidenciando o efeito positivo da adição de outros componentes ao substrato comercial sobre essas características, fato que não foi verificado no presente trabalho com a adição do resíduo de sisal ao Tropstrato ${ }^{\circledR}$.

Maior valor de massa seca de raízes foi verificado quando se utilizou apenas o substrato comercial, embora não tenha diferido significativamente dos substratos em que incorporou-se 10, 40, 50 e $80 \%$ do RSL. Filgueira (2003) afirma que um bom enraizamento e o reinício do desenvolvimento da planta, após o choque do processo de transplante são favorecidos por tecidos ricos em matéria seca.

Não houve diferença significativa entre os diferentes substratos estudados no índice de velocidade e porcentagem de emergência de sementes de brócolis (Tabela 2).

Tabela 2 - Características de plântulas de brócolis cultivadas em substratos compostos por diferentes proporções do resíduo de sisal (RSL) incorporado ao substrato comercial Tropstrato ${ }^{\circledR}$. Juazeiro-BA, 2011

\begin{tabular}{|c|c|c|c|c|c|c|c|c|c|}
\hline \multirow[b]{2}{*}{ Substrato $^{1}$} & \multicolumn{9}{|c|}{ Características $^{2}$} \\
\hline & IVE & $\% \mathrm{E}(\%)$ & CPA (cm) & CR $(\mathbf{c m})$ & DC (mm) & NF & $\operatorname{VR}\left(\mathrm{cm}^{3}\right)$ & $\begin{array}{c}\text { MSPA } \\
\text { (mg) }\end{array}$ & $\begin{array}{c}\text { MSR } \\
\text { (mg) }\end{array}$ \\
\hline $0 \% \mathrm{RSL}$ & $2,45 \mathrm{a}$ & $35,62 \mathrm{a}$ & $3,02 \mathrm{a}$ & $11,41 \mathrm{a}$ & $0,69 \mathrm{a}$ & $2,45 \mathrm{c}$ & $0,150 \mathrm{abc}$ & $2,6 \mathrm{a}$ & $6,0 \mathrm{a}$ \\
\hline $10 \%$ RSL & $2,43 \mathrm{a}$ & $31,87 \mathrm{a}$ & $2,89 \mathrm{a}$ & $10,98 \mathrm{a}$ & $0,81 \mathrm{a}$ & $2,78 \mathrm{abc}$ & $0,097 \mathrm{bc}$ & $3,2 \mathrm{a}$ & $4,2 \mathrm{a}$ \\
\hline $20 \% \mathrm{RSL}$ & $2,97 \mathrm{a}$ & $42,50 \mathrm{a}$ & $2,34 \mathrm{a}$ & $12,05 \mathrm{a}$ & $0,78 \mathrm{a}$ & $2,52 \mathrm{abc}$ & $0,075 \mathrm{c}$ & $2,9 \mathrm{a}$ & $8,0 \mathrm{a}$ \\
\hline $30 \% \mathrm{RSL}$ & $2,35 \mathrm{a}$ & $35,00 \mathrm{a}$ & $2,79 \mathrm{a}$ & $10,75 \mathrm{a}$ & $0,79 \mathrm{a}$ & $2,50 \mathrm{bc}$ & $0,150 \mathrm{abc}$ & $2,5 \mathrm{a}$ & $4,7 \mathrm{a}$ \\
\hline $40 \%$ RSL & $2,78 \mathrm{a}$ & $41,87 \mathrm{a}$ & $3,02 \mathrm{a}$ & $10,56 \mathrm{a}$ & $0,90 \mathrm{a}$ & $2,92 \mathrm{ab}$ & $0,212 \mathrm{a}$ & $3,4 \mathrm{a}$ & $5,5 \mathrm{a}$ \\
\hline $50 \%$ RSL & $3,25 \mathrm{a}$ & $45,62 \mathrm{a}$ & $3,38 \mathrm{a}$ & $11,03 \mathrm{a}$ & $0,75 \mathrm{a}$ & $2,95 \mathrm{a}$ & $0,205 \mathrm{ab}$ & $4,2 \mathrm{a}$ & $7,7 \mathrm{a}$ \\
\hline $60 \%$ RSL & $2,75 \mathrm{a}$ & $41,25 \mathrm{a}$ & $2,21 \mathrm{a}$ & $10,62 \mathrm{a}$ & $0,69 \mathrm{a}$ & $2,80 \mathrm{abc}$ & $0,192 \mathrm{ab}$ & $3,0 \mathrm{a}$ & $6,2 \mathrm{a}$ \\
\hline $80 \%$ RSL & $2,44 \mathrm{a}$ & $36,67 \mathrm{a}$ & $3,01 \mathrm{a}$ & $11,39 \mathrm{a}$ & $0,73 \mathrm{a}$ & $2,67 \mathrm{abc}$ & $0,187 \mathrm{ab}$ & $2,8 \mathrm{a}$ & $6,7 \mathrm{a}$ \\
\hline $\mathrm{CV}(\%)$ & 25,23 & 25,17 & 11,99 & 13,96 & 12,40 & 7,09 & 29,12 & 31,24 & 23,94 \\
\hline
\end{tabular}

${ }^{\mathrm{I}}$ Médias seguidas de mesma letra nas colunas não diferem entre si pelo teste Tukey, a 5\% de probabilidade.

${ }^{2}$ IVE: Índice de velocidade de emergência; \%E: porcentagem de emergência; CPA: comprimento de parte aérea; CR: comprimento de raiz; DC: Diâmetro de colo; NF: Número de folhas; VR: volume de raiz; MSPA: massa seca da parte aérea; MSR: massa seca de raiz. 
De modo geral, observa-se que a porcentagem de emergência das sementes de brócolis nas condições em que o experimento foi conduzido foi baixa. Isso pode ter ocorrido por conta das altas temperaturas médias no local de estudo. Segundo Filgueira (2003) para seu bom desenvolvimento, o brócolis requer clima ameno ou temperado. Trevisan et al. (2003) citam que as melhores temperaturas médias para as brássicas são em torno de 15 a $18{ }^{\circ} \mathrm{C}$.

As características comprimento de parte aérea e de raiz das plântulas de brócolis também não diferiram significativamente entre si. Silveira et al. (2002) verificaram que a adição de húmus de minhoca e pó de coco ao Plantmax ${ }^{\circledR}$, em proporções iguais, promoveram maiores valores de altura de plantas de tomateiro quando comparado a utilização do Plantmax $^{\circledR}$ individualmente. Quanto ao desenvolvimento das raízes, segundo Santos et al. (2010) a utilização de resíduos orgânicos na composição de substratos para o cultivo de mudas contribui sensivelmente com a aeração, capacidade de retenção de água e formação de uma estrutura física adequada ao desenvolvimento das mesmas, no entanto, no presente trabalho, a incorporação de até $80 \%$ do RSL não promoveu diferenças nos valores dessas características quando comparado a utilização do substrato comercial individualmente.

Não houve diferença significativa entre os substratos no diâmetro de colo das plântulas de brócolis. Quanto ao número de folhas, maiores valores foram obtidos quando incorporado $50 \%$ do RSL ao substrato comercial, embora não tenha diferido significativamente dos substratos compostos por 10, 20, 40, 60 e $80 \%$ do RSL. Diniz et al. (2006) verificaram que a adição de 0, 10, 20 e 40\% de vermiculita ao húmus não promoveram diferença significativa em comparação a utilização de Plantmax ${ }^{\circledR}$ como substrato no número de folhas de mudas de tomate e de pimentão, avaliadas aos 25 e 36 DAS, respectivamente.

O maior volume de raízes das plântulas de brócolis foi obtido quando incorporou-se $40 \%$ do RSL ao substrato comercial, embora tenha diferindo significativamente apenas dos substratos em que foram incorporados 10 e $20 \%$ do RLS. Segundo Guerrini e Trigueiro (2004), os substratos comerciais têm como característica porcentagem de microporos considerada adequada para a produção de mudas de hortaliças, o que lhes confere capacidade de retenção de água satisfatória, influenciando positivamente o desenvolvimento do sistema radicular das mudas. No entanto, Santos et al. (2010) afirmam que a utilização de resíduos orgânicos na composição de substratos para o cultivo de mudas contribui sensivelmente com a aeração, capacidade de retenção de água e formação de uma estrutura física adequada ao desenvolvimento das raízes.

Não houve diferença significativa entre os substratos nas massas secas de parte aérea e de raízes. Diferente dos resultados obtidos no presente trabalho, Costa et al. (2013) verificaram maiores valores de massa seca, tanto de raiz quanto de parte aérea de plântulas de tomateiro, quando utilizado composto orgânico e a mistura de composto orgânico + areia, nas proporções de 3:1, 1:1 e 1:3, como substrato, comparado ao substrato comercial Plantmax ${ }^{\circledR}$. Esses mesmos autores avaliando os mesmos substratos na cultura do pepino também verificaram que o Plantmax ${ }^{\circledR}$ induziu menores valores de massa seca de parte aérea, diferindo significativamente dos demais, no entanto não obtiveram diferença significativa na massa seca de raiz. Smirdele et al. (2001) verificaram que a adição de solo ao Plantmax $^{\circledR}$ na proporção de 1:1 não diferiu significativamente de quando utilizado apenas o Plantmax ${ }^{\circledR}$ como substrato na massa seca de parte aérea e de raízes de mudas de pepino e pimentão.

\section{CONCLUSÕES}

O resíduo de sisal pode ser incorporado ao substrato comercial Tropstrato ${ }^{\circledR}$ na formação de mudas de jiló e brócolis sem interferir na sua qualidade, sendo mais indicada a incorporação de $50 \%$ do resíduo de sisal ao substrato comercial.

\section{REFERÊNCIAS BIBLIOGRÁFICAS}

CARRIJO, O.A.; LIZ, R.S.; MAKISHIMA, N. Fibra da casca do coco verde como substrato agrícola. Horticultura Brasileira, Brasília, v. 20, n. 4, p. 533-535, 2002. DOI: http://dx.doi.org/10.1590/S0102-05362002000400003

COSTA, C.A.; RAMOS, S.J.; SAMPAIO, R.A.; GUILHERME, D.O; FERNANDES, L.A. Fibra de coco e resíduo de algodão para substrato de mudas de tomateiro. Horticultura Brasileira, Brasília, v. 25, n. 3, p. 387-391, 2007. DOI: http://dx.doi.org/10.1590/S0102-05362007000300013

COSTA, L.A.M.; COSTA, M.S.S.M.; PEREIRA, D.C.; BERNARD, F.H.; SILVIA, M. Avaliação de substratos para a produção de mudas de tomate e pepino. Revista Ceres, Viçosa, v. 60, n.5, p. 675-682, 2013. DOI: http://dx.doi.org/10.1590/S0034-737X2013000500011

DINIZ, K.A.; GUIMARÃES, S.T.M.R.; LUZ, J.M.Q. Húmus como substrato para formação de mudas de tomate pimentão e alface. Biosciense Journal, Uberlandia, v. 22, n. 3, p. 63-70, 2006.

FILGUEIRA, F.A.R. Novo manual de olericultura: agrotecnologia moderna na produção e comercialização de hortaliças. 2. ed. Viçosa: UFV, 2003.

GOMES, L.A.A.; RODRIGUES, A.C.; COLLIER, L.S.; FEITOSA, S.S. Produção de mudas de alface em substrato alternativo com adubação. Horticultura Brasileira, Brasília, v. 26, n. 3, p. 359-363, 2008. DOI: http://dx.doi.org/10.1590/S0102-05362008000300013

GRASSI FILHO, H.; SANTOS, C.H. Importância da relação entre os fatores hídricos e fisiológicos no desenvolvimento de plantas cultivadas em substratos. In: BARBOSA, J.G.; MARTINEZ, H.E.P.; PEDROSA, M.W; SEDIYAMA, M.A.N. (Eds.). Nutrição e adubação de plantas cultivadas em substrato. Viçosa: UFV, p. 78-79. 2004.

GUERRINI, I.A.; TRIGUEIRO, R.M. Atributos físicos e químicos de substratos compostos por biossólidos e casca de arroz carbonizada. Revista Brasileira de Ciência do Solo, Viçosa, v. 28, n. 6, p. 1069-1076, 2004. 
LAVIOLA, B.G.; LIMA, P.A.; JÚNIOR, A.W.; MAURI, A.L.; VIANA, R.S. LOPES, J.C. Efeito de diferentes substratos na germinação e no desenvolvimento inicial de jiloeiro (Solanum gilo RADDI), cultivar Verde Claro, Ciência e Agrotecnologia, Lavras, v. 30, n. 3, p. 415421, 2006. DOI: http://dx.doi.org/10.1590/S141370542006000300005

MAGUIRE, J.D. Speed of germination - aid in selection and evaluation for seedling emergence and vigor. Crop Science, v. 2, p. 176-177, 1962.

MAURI, J.; LOPES, J.C.; FERREIRA, A.; AMARAL, J.F.T.; FREITAS, A.R. Germinação e desenvolvimento inicial da plântula de brócolos em função de substratos e temperaturas. Scientia Agraria, Piracicaba, v.11, n. 4, p. $275-280,2010$.

OLIVEIRA, R.B.; LIMA, J.S.S.; SOUZA, C.A.M.; SILVA, S.A.; MARTINS FILHO, S. Produção de mudas de essências florestais em diferentes substratos e acompanhamento do desenvolvimento em campo. Ciência e Agrotecnologia, Lavras, v. 32, n. 1, p. 122128, 2008. DOI: http://dx.doi.org/10.1590/S141370542008000100018

SANTOS, M.R.; SEDIYAMA, M.A.N.; SALGADO, L.T.; VIDIGAL, S.M.; REIGADO, F.R. Produção de mudas de pimentão em substratos à base de vermicomposto. Biosciense Journal, Uberlandia, v. 26, n. 4, p. 572-578, 2010.

SILVA, F.A.S.; AZEVEDO, C.A.V. Versão do programa computacional ASSISTAT para o sistema operacional Windows. Revista Brasileira de Produtos
Agroindustriais, Campina Grande, v. 4, n. 1, p. 71-78, 2002.

SILVEIRA, E.B.; RODRIGUES, V.J.L.B.; GOMES, A.M.A.; MARIANO, R.L.R.; MESQUITA, J.C.P. Pó de coco como substrato para produção de mudas de tomateiro. Horticultura Brasileira, Brasília, v. 20, n. 2, p. 211 216, 2002. DOI: http://dx.doi.org/10.1590/S010205362002000200019

SMIDERLE, O.J.; SALIBE, A.B.; HAYASHI, A.H.; MIAMI, K. Produção de mudas de alface, pepino e pimentão em substratos combinando areia, solo e Plantmax $^{\circledR}$. Horticultura Brasileira, Brasília, v. 19, n. 3, p. 253-257, 2001. DOI: http://dx.doi.org/10.1590/S0102-05362001000300022

TEIXEIRA, A.H.C. Informações agrometeorológicas do Polo Petrolina, PE/Juazeiro, BA - 1963 a 2009. Documentos [da] Embrapa Semiárido, Petrolina, PE, n. 233, p. 1 21, 2010.

TREVISAN，J.N.; MARTINS，G.A.K.; LÚCIO， A.D.C.; CASTAMAN, C.; MARION, R.R.; TREVISAN, B.G. Rendimento de cultivares de brócolis semeadas em outubro na região centro do Rio Grande do Sul. Ciência Rural, Santa Maria, v. 33, n. 2, p. 233-239, 2003.

VALE, L.S.; COSTA, J.V.T.; ANUNCIAÇÃO FILHO, C.J.; LIMA, R.L.S. Efeito de diferentes misturas de substrato e tamanho de recipientes na produção de mudas mamoeiro. In: BARBOSA, J.G.; MARTINEZ, H.E.P.; PEDROSA, M.W. Nutrição e adubação de plantas cultivadas em substrato. Viçosa: UFV, p. 385. 2004. 